\title{
Ethnic Considerations of Choice of Livelihood Coping Strategies to Combat Climate Change and Variability: A Gender Perspective
}

\author{
Katherine Kaunza Millar ${ }^{1}$, Mark McCarthy Akrofi ${ }^{2}$, David Millar ${ }^{3}$ \\ ${ }^{1,2}$ Department of Planning, Faculty of Planning and Land Management, University Post Wa, \\ University for Development Studies. Wa Campus. \\ ${ }^{3}$ Faculty of Integrated Development Studies, University for Development Studies-Wa Campus, Ghana

\begin{abstract}
Humans by nature make efforts to cope with climate variability and change, however, adaptation to climate change manifest in varied ways and forms. From an ethnic and gender perspective, this study examined the choice of livelihood coping strategies in the face of climate variability in the Kasena- Nankana Municipality and the Bongo District in the Upper East Region of Ghana. The concurrent mixed method approach was used.Hence, both qualitative and quantitative data collection and inference techniques were combined. A sample size of 312 rural farmers (194 males and 118 females; age range of 18-73 years), were involved in the study. Two Focus Group Discussions (between 8 to 12 members each) were conducted in each community. The Chi-square test revealed that, coping strategies such as planting of trees and shrubs on farmlands, growing different varieties of crops, collecting and storing grass during the rainy season, among others had very significant relationships with ethnicity, with $P$ Values of less than .001 ( $P<.001)$. Gender however, didn't have a significant relationship with coping strategies adopted as P-Values for all coping strategies except collecting and storing of grasses during the rainy season $\left(x^{2}=4.41, p=0.04\right)$ were greater than the significance level of 0.05 .
\end{abstract}

Keywords: Coping Strategy; Ethnicity, Gender; Climate Variability, Climate Change; Agricultural Livelihoods.

\section{INTRODUCTION}

The greater proportion of people in developing countries engage in livelihood activities relating to agricultural activities and therefore, greatly feel the impact of climate variability than the developed countries (Obiri-Opare and Onumah, 2014 ${ }^{[1]}$; International Panel on Climate Change (IPCC), 2007 $7^{[2]}$ ). In climate change literature, it has been established that, humans by nature make efforts to cope or adapt to this phenomenon (Smit \& Pilifosova, 2003 ${ }^{[3]}$ : Berkes \& Jolly 2001 ${ }^{[5]}$ : Bryant et al., $2000^{[6]}$ ). Generally, coping mechanisms are the actual responses to crisis on livelihood systems in the face of unwelcomed situations, and are considered as short-term responses (Berkes \& Jolly $2001^{[4]}$ ). Adaptation to climate change manifest in varied ways and forms.Thus, how adaptation occurs has been differentiated according to numerous attributes (Leary, 1999 ${ }^{[6]}$; Bryant et al., 2000 ${ }^{[5]}$; Reilly and Schimmelpfennig, $2000^{[7]}$ ) based on the context and scale of consideration. The impacts of climate variability are anticipated to disproportionately affect the well-being of the poor in rural communities, such as female-headed households and people with limited access to land, advanced agricultural inputs, infrastructure, and education.

Although several researches have been conducted with regards to the impacts of climate change, such researches are not detailed about the potential role of smallholder farmers in their adaptation responses (Antwi-Agyei, 2012 ${ }^{[8]}$ ). Most of the researches on adaptations are very general; with rare attempts at cross-comparisons between two different Districts or Traditional Areas of northern Ghana. Very little yet is also available on gender cross-comparisons. Webb and Reardon (1992) ${ }^{[9]}$ argued that most studies have tried to identify general patterns of coping rather than differentiating between agroecological zones, villages and types of households. Moreover, adaptation practices are not yet completely explored and little is known about the rationality and/or determinants of local adaptation strategies due to inadequate knowledge and documentation. 
Working Group 2 of the IPCC defines adaptation as; adjustment in natural or human systems in response to actual or expected climatic stimuli or their effects, which moderates harm or exploits beneficial opportunities (IPCC,2007) ${ }^{[2]}$. As illustrated in Figure 1, adaptation to climate change is conceptualized as a continuum with activities ranging from a vulnerability focus that addresses the underlying drivers of vulnerability to a more impact-oriented focus that includes measures or actions that reduce the impacts of climate change or takes advantage of them (such as dikes or irrigation measures) (van Noordwijk et al., 2011) ${ }^{[10]}$

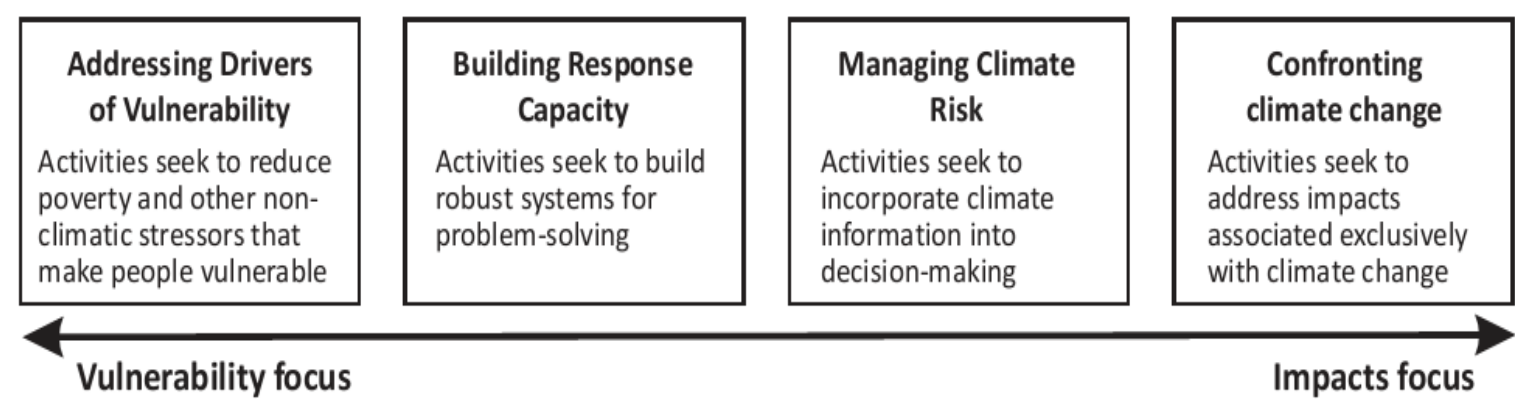

Figure 1. Adaptation as a continuum (van Noordwijk et al., 2011) ${ }^{[10]}$

Smit and Pilifosova, $2003^{[3]}$ note that, though there are many attributes used in classifying forms of adaptation, the commonly used distinctions are purposefulness and timing. In the aspect of purpose, autonomous and planned adaptation has been identified (Smit \& Pilifosova, 2003) ${ }^{[3]}$. Autonomous or spontaneous adaptations occur when actors react to climate variability. In this case, it is the kind of adaptation, which is not planned, but only occurs to respond to climate variability after its effects has been realized. For planned adaptation, it is the situation where actors put in place measures in anticipation of climate variability. This is based on some form of forecast.

Studies conducted by Frederick (2014) ${ }^{[11]}$, Webber (1996a) ${ }^{[12]}$ and Blench (2006) ${ }^{[13]}$ provide substantive evidence of climate variability and change in the region in which this study was conducted (the Upper East Region of Ghana).Frederick (2014) ${ }^{[11]}$ in the study of threats to food security in the Kassena-Nankana Municipality outlined compelling evidence of climate change in the area. These evidences ranged from rainfall patterns to temperatures experienced over the years.

Also, Webber (1996a ${ }^{[12]}$ describing the extreme northeast, quotes the mean for 1955-1992 as $956 \mathrm{~mm}$ with a range of 682-1310 mm. The rain falls in a six-month season, from April to September. Rainfall can be very patchily distributed and farmers often plant seeds two or three times before the rains set in reliably. It is widely believed throughout the region, by administrators as much as farmers, that the overall quantity of rain falling is declining and that the distribution is more unfavorable than before Blench (2006) ${ }^{[13]}$.

The declining amounts of rainfall, unpredictability of incidence and duration of agro-seasons and rains resulting from rising temperatures and variation of rainfall patterns are threatening rural livelihoods. Various coping mechanisms are thus adopted by rural farmers in order to maintain their livelihoods within the region. Yet the potential role of smallholder households in climate variability and change adaptation, per gender and across localities, is not fully explored. This study is therefore situated in understanding how ethnicity and gender influence the choice of livelihood coping strategies to deal with climate variability and change among rural farmers in the Kasena-Nankana Municipality and the Bongo District in the Upper East Region of Ghana.

\section{MATERIALS AND MethodS}

\subsection{The Study Areas}

The study was conducted in the Kassena-Nankana and Bongo Districts in the Upper East Region of Ghana, which is predominantly rural. Figure 5shows the location of the two districts and the respective study communities. Agriculture is the backbone of the local economy of both districts with the agricultural sector employing about 65.4 percent and 72.2 percent of the employable population in the Kassena-Nankana and Bongo Districts respectively. The above review of literature has shown clearly that variability is evident in the two districts. These two districts have distinct ethnic grouping and different livelihood approaches; hence allows for cross-comparison of findings. 


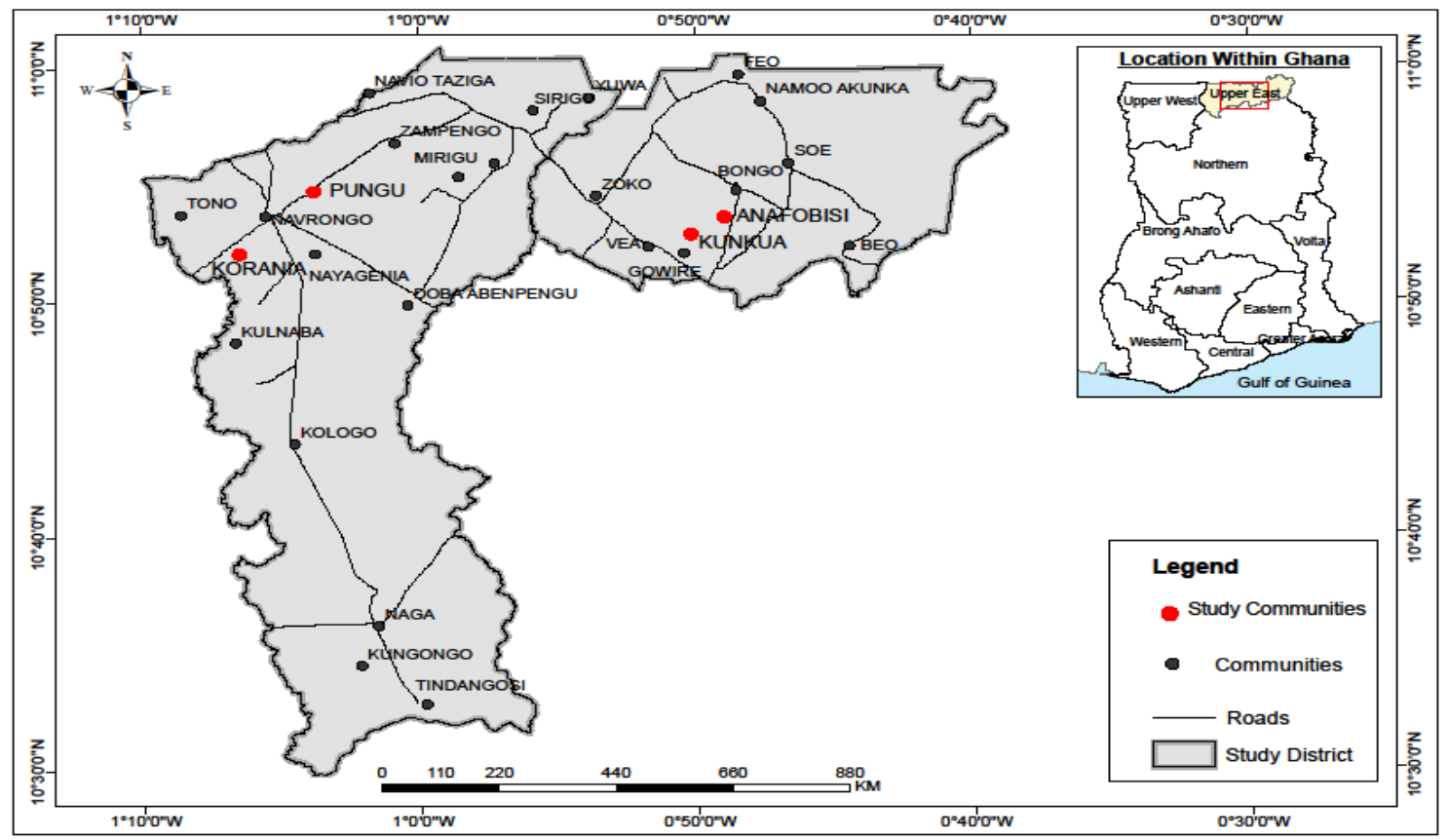

Figure 2. Map Showing the study Districts and their respective study communities. (Kassena- Nankana Municipal Assembly, 2014) ${ }^{[14]}$.

\subsection{Study Design and Methods}

The study employed the mixed method approach (see Creswell, 2009) ${ }^{[15]}$. Hence, both qualitative and quantitative viewpoints, data collection techniques and inference techniques were combined in this study. Specifically, the study adopts the comparative research approach. This involves a comparative study between the Kassena-Nankana and Bongo Districts as a means of understanding how they adapt to climate change and variability, highlighting their similarities and differences. The study population includes rural households in the Kassena-Nankana Municipality and Bongo District, key informants within communities and institutions of interest to rural livelihoods in the study area. In the context of this research, emphasis is placed on Kassena households in Kassena-Nankana Municipality and Gruni households in the Bongo District. This is because; the study focuses on understanding how the two ethnic groups adapt to climate change and variability.

In all, the sample frame was made up 1379 households in the four selected communities. With the sample frame derived, the sample size was calculated using the formula $\mathrm{n}=\frac{\mathrm{N}}{1+\mathrm{N}\left(\alpha^{2}\right)}$ with $95 \%$ confidence level and 0.05 margin of error, where $n=$ the sample size, $N=$ the population and $\alpha=$ margin of error to accept at that sample size (Israel, 2013) ${ }^{[16]}$.A total sample size of 312 was obtained and equally distributed among the four communities.

A multi-stage sampling technique was adopted with each stage carried out with a unique technique. This involved both probability and non-probability sampling techniques. The purposive sampling technique was adopted to select the study districts. The Kassena Nankana and bongo districts were thus purposefully selected based on earlier evidence of the negative effects of climate change on rural livelihoods in the area. Also, purposive sampling was used to select relevant institutions, including the agricultural units of each district to be interviewed due to their knowledge on Agri-related livelihoods which forms the focus of this study. Random sampling technique was adopted to select two communities in each district. At the community level, intuition was used to select 78 respondents in each based on relevant literature on mixed methods. Selection of the actual 78 household respondents was based on convenience sampling. Households were conveniently sampled to be interviewed in the study. Households who were readily available at the time of the study were therefore interviewed. However, stratification was applied to ensure distribution of respondents among different Agri-related activities undertaken in the study areas. In line with this, some kind of arbitrary segregation was done to ensure respondents were not skewed towards one specific Agri-related livelihood. 
Primary data were collected from households (both males and females) in the four communities. Secondary data on the other hand were obtained from both published and unpublished reports; journal articles, institutional reports (Statistical Service Report, District Development Plans) and other studies related to the subject matter and the study zone. A set of structured questions (both pre-coded and open-ended) were designed based on the objectives of the study; administered by the researcher and other trained research assistants to elicit information from households (males and females).Interview was a technique used in gathering data from relevant institutions in the study areas. Focused group discussion was used as a method of collecting qualitative data. Two focused group discussions were conducted in each of selected communities; farmer group (mainly of males) and women's group. Each group had membership ranging from $8-12$ depending on the availability of the people at that time. Data obtained was analyzed by means of SPSS Software. The univariate data analysis was used to analyze the basic descriptive characteristics of the study population and data about their livelihood situation. Qualitative data were summarized and reduced to a manageable size. The manageable size data were then discussed and used to back quantitative data. All quotations were presented verbatim in order to present a true reflection of the voices of the participants.

\section{RESULTS AND DiSCUSSIONS}

\subsection{Demographic Characteristics of Respondents}

$69.2 \%$ of the respondents were males whiles $30.8 \%$ were females for the two districts. However, $32.1 \%$ and $37.1 \%$ were males whiles $17.9 \%$ and $12.9 \%$ were females in Bongo district and KassenaNankana district respectively. Male dominance among respondents in both study areas is attributed to the fact that heads of households formed the basis for household livelihood activity assessment. The finding confirms the fact that males are the most dominant heads of households in many areas in Ghana, especially in rural communities (Ghana Statistical Service, 2014) ${ }^{[17]}$.In both districts, majority (27.6 percent and 28.2 percent for Bongo and Kassena-Nankana respectively) of respondents were between the ages of 50-70 years. Generally, about 56.4 percent were between the ages of 50-70 years. Respondents above the ages of 70 years formed minority in both districts, recording 6.7 percent and 4.2 percent in Bongo District and Kasena-Nankana District respectively.

\subsection{Indigenous Livelihood Coping Strategies among the Gruni and Kassena}

The study revealed that, many strategies are adopted by both males and females among the two groups to cope with climate variability. Generally, strategies adopted with regard to crop farming included growing shrubs on farms, planting more trees on farms, practicing irrigation farming, growing different crops, among others. In the aspect of animal production, both Gruni and Kassena resort to regular vaccination of stocks. The strategies were mainly about diversifying livelihood options and trying to minimize the effects on natural resources which activities depend on. One interesting finding is the use of sacrifice (21.1 percent) among the Kassena in an attempt to cope with climate change. With this, respondents noted that, climate variability has something to do with the gods, so sacrifice and pacifying them will help reduce the way they suffer from its effects. This strategy was however not found among the Gruni.

Table 1. Coping Strategies Adopted by Gruni and Kassena

\begin{tabular}{|l|l|l|}
\hline \multirow{2}{*}{ Strategy } & Percentage of Responses (\%) \\
\cline { 2 - 3 } & $\begin{array}{l}\text { Bongo District } \\
\text { (Gruni) }\end{array}$ & $\begin{array}{l}\text { KassenaNankana Municipality } \\
\text { (Kassena) }\end{array}$ \\
\hline Planting trees and shrubs on farmlands & 22.5 & 49.1 \\
\hline Making water barriers to check erosion & 22.9 & 0.9 \\
\hline Making compost & 30 & 18.9 \\
\hline Practicing irrigation farming & 10 & 15.1 \\
\hline Growing different varieties of crops & 7.3 & 31.1 \\
\hline Increase the farm size & 7.3 & 7.5 \\
\hline Vaccinating and deworming animals & 15.1 & 2.8 \\
\hline Planting crops that take a little time to mature & 23.6 & 15.0 \\
\hline Collect and store grass during the rainy season & 45.2 & 17.0 \\
\hline Fish only in the rainy season & 11.8 & 7.5 \\
\hline Making sacrifice & - & 21.1 \\
\hline Total & $\mathbf{1 0 0 . 0}$ & $\mathbf{1 0 0 . 0}$ \\
\hline
\end{tabular}

(Author's Field Survey, June 2016) 
From Table 1, both Gruni and Kasena resort to diverse strategies in order to cope with climate change. These ranged from direct efforts to improve productivity by both groups to spiritual efforts aimed at pleasing gods to intervene by the Kassena.

Both Gruni and Kassena viewed their own adopted strategies in diverse ways in terms of effectiveness. Though many of these people saw their strategies as efficient/effective, a significant number (39.2 percent of Gruni and 43.8 percent of Kassena) harbored doubts on their adopted strategies. These people viewed their strategies as fairly efficient/effective (See Table 4.20). Respondents noted that, they cannot have full confidence in their strategies because they continue to experience the effects despite making so much effort. This means that, there is no absolute trust in the indigenous strategies adopted by these two ethnic groups.

Table 2. Respondents Assessment of Efficiency of Own Strategies

\begin{tabular}{|l|l|l|l|}
\hline \multirow{2}{*}{$\begin{array}{l}\text { Level } \\
\text { Efficiency/Effectiveness }\end{array}$} & \multicolumn{3}{l|}{ Percentage of Responses (\%) } \\
\cline { 2 - 4 } & Bongo District & KassenaNankana Municipality & Total \\
\hline Very Effective/ Very Efficient, & 16.0 & 11.6 & 13.9 \\
\hline Effective/ Efficient & 44.0 & 38.4 & 41.4 \\
\hline Fairly Effective/ Fairly Efficient & 39.2 & 43.8 & 41.4 \\
\hline Not Effective/ Not Efficient & .8 & 6.3 & 3.4 \\
\hline Total & $\mathbf{1 0 0 . 0}$ & $\mathbf{1 0 0 . 0}$ & $\mathbf{1 0 0 . 0}$ \\
\hline
\end{tabular}

(Author's Field Survey, June 2016)

\subsection{The Role of Gender in Choice of Coping Strategies}

The study also revealed that gender plays little or no role in the kind of coping strategy adopted. The activity undertaken by an individual and available resources influences the strategy adopted. Though males and females among the Gruni and the Kassena adopt similar coping strategies, their ability to cope were not the same. One example of difference in strategy was the use of increasing land size to cope. With this strategy, only male respondents attested to this among both ethnic groups. Females noted that, there was limited land available to them so using such a strategy was not an option they could explore. This finding confirms how culture limits women access to land among many ethnic groups in sub-Sahara Africa (Ministry of Environment, Science, Technology and Innovation (MEST), $2013^{[18]}$ : Whitehead \& Tsikata, 2003 $\left.{ }^{[19]}\right)$. In almost all communities, female responses on coping strategies showed their ability being limited. A female participant asserted that ".......we try our best to have our lives, but sometimes that support is not just there for us. I suffer with my children to farm, but this is always at the mercy of the rains" This was further confirmed by another female participant who noted that "...mostly the men are our leaders, so whenever help come, they get it. We try our best but I think they are well placed in coping with the current situation than us" To many of these women, climate change is a threat to their livelihoods more than the men. This is due to their limited capacities to adopt or cope with the situation. This confirms the assertion that climate change is a threat to livelihoods, but poses more problems to females than males (MEST, 2013 ${ }^{[18]}$ : Paavola, $2008^{[20]}$ : Denton, $\left.2002^{[21]}\right)$.

\subsection{Statistical Relationships of Identified Coping Strategies}

In analyzing the relations between ethnicity (among the Gruni and Kassina) and coping strategies adopted to minimize the effect of climate change in the area, applying the chi-square test statistics, a mix of relationships were identified. Thus, some coping strategies had statistical significant relationships with ethnicity and gender whiles others did not have. Considering the $95 \%$ confidence level adopted in the methodology for sampling, a $P$ value of $.05(P=.05)$ serves as the benchmark for determining significance of relationships.

From chi-square statistics of various coping strategies, there exist both significant and insignificant relationships with ethnicity. Hence, most of the coping strategies such as planting of trees and shrubs on farmlands, making water barriers to check erosion, growing different varieties of crops, vaccinating and deworming animals, and collecting and storing grass during the rainy season had very significant relationships with ethnicity in the areas since their $P$ Values were .000 which is less than .05 (see Table 3). 
Katherine Kaunza Millar et al.

Table 3. Relationship between Ethnicity and Coping Strategies Adopted

\begin{tabular}{|l|l|l|}
\hline \multirow{2}{*}{ Strategy } & Chi-Square Values \\
\cline { 2 - 3 } & Pearson Chi-Square & Asymp. Sig. P-Value \\
\hline Planting trees and shrubs on farmlands & 16.82 & 0.00 \\
\hline Making water barriers to check erosion & 25.45 & 0.00 \\
\hline Making compost & 3.61 & 0.57 \\
\hline Practicing irrigation farming & 1.28 & 0.26 \\
\hline Growing different varieties of crops & 19.71 & 0.00 \\
\hline Increase the farm size & 0.00 & 0.95 \\
\hline Vaccinating and deworming animals & 11.93 & 0.00 \\
\hline Planting crops that take a little time to mature & 2.55 & 0.11 \\
\hline Collect and store grass during the rainy season & 16.90 & 0.00 \\
\hline Fish only in the rainy season & 0.91 & 0.63 \\
\hline Making sacrifice & - & - \\
\hline
\end{tabular}

(Authors Own Construct, June 2016)

Table 4. Relationship between Gender and Coping Strategy Adopted

\begin{tabular}{|l|l|l|}
\hline \multirow{2}{*}{ Strategy } & Chi-Square Values \\
\cline { 2 - 3 } & Pearson Chi-Square & Asymp. Sig. P-Value \\
\hline Planting trees and shrubs on farmlands & 0.58 & 0.45 \\
\hline Making water barriers to check erosion & 3.49 & 0.06 \\
\hline Making compost & 0.39 & 0.53 \\
\hline Practicing irrigation farming & 0.12 & 0.73 \\
\hline Growing different varieties of crops & 0.59 & 0.81 \\
\hline Increase the farm size & 0.79 & 0.36 \\
\hline Vaccinating and deworming animals & 0.16 & 0.69 \\
\hline Planting crops that take a little time to mature & 0.97 & 0.33 \\
\hline Collect and store grass during the rainy season & 4.41 & 0.04 \\
\hline Fish only in the rainy season & 0.20 & 0.65 \\
\hline Making sacrifice & 0.87 & 0.35 \\
\hline
\end{tabular}

(Authors Own Construct, June 2016)

\section{Conclusion}

From the discussions, it can be concluded that, rural farmers in the Kasena-Nankana Municipality and the Bongo District in the Upper East Region of Ghana practice both autonomous and planned adaption as some of them use reactive measures such as making water barriers and practising irrigation farming whiles others take proactive measures such as collecting and storing grasses during the rainy season in order to use it as fodder during the dry season.Generally, there is no significant relationship between gender and coping strategy adopted. Hence, one's gender does not determine the kind of coping strategy he or she adopts. Ethnicity can however be said to influence the kind of coping strategies adopted. This is because, certain coping strategies such as planting trees and shrubs on farmlands, making water barriers to check erosion among others have a significant relationship with cross-ethnic comparison. Hence, the possibility of adopting these strategies depends on either the person is a Kassena or Gruni. Since the possibility of adopting certain coping strategies depends on gender or ethnicity, efforts must be made to mainstream these elements into designing coping strategy programs aimed at improving rural lives. Hence, various coping strategies must be well examined to identify elements which tend to affect their adoption, and if possible their effectiveness ultimately.

\section{REFERENCES}

[1] Obiri-Opare, N., and Onumah, J. A., Climate Change Impact Pathways on Agricultural Productivity in Africa: A Review, Journal of Environmental and Earth Science, 4(4), (2014): 115-121.

[2] IPCC., Climate Change 2007: Impacts, Adaptation and Vulnerability. Contribution of Working Group II to the Fourth Assessment Report of the Intergovernmental Panel on Climate Change,(2007), Glossary, pp. 869-883. M.L. Parry, O.F. Canziani, J.P. Palutikof, P.J. van der Linder \& C.E. Hanson eds. Cambridge, UK, Cambridge University Press. 
[3] Smit, B., and Pilifosova, O., Adaptation to climate change in the context of sustainable development and equity. Sustainable Development, 8(9), 9(2003).

[4] Berkes, F. and Jolly, D., Adapting to climate change: Social-Ecological resilience in Canadian Western Arctic community. Conservation Ecology 5(2), 18(2001).

[5] Bryant, C.R., Smit, B., Brklacich, M., Johnston, T. R., Smithers, J., Chiotti, Q., and Singh, B., Adaptation in Canadian agriculture to climatic variability and change. Climatic Change, 45(1), (2000):181-201.

[6] Leary, N. Climate change and adaptation, Earthscan: London-UK, (2012).

[7] Reilly, J. and D. Schimmelpfennig., Irreversibility, uncertainty, and learning: portraits of adaptation to long-term climate change. Climatic Change, 45(1), (2000):253-278.

[8] Antwi-Agyei, P., Stringer, L. C., and Dougill, A. J., Livelihood adaptations to climate variability: insights from farming households in Ghana. Regional environmental change, 14(4), (2014): $1615-1626$.

[9] Webb, P. and Reardon, T., Drought Impact and Household Response in East and West Africa. Quarterly. Journal of International Agriculture 31 (3),(1992): 230-247.

[10] van Noordwijk, M., Hoang, M.H., Neufeldt, H., ÖBORN, I. and YATICH, T., How trees and people can co-adapt to climate change. Reducing vulnerability in multifunctional landscapes, (2011):136.

[11] Frederick, A., Emerging Threats to Food Security among Rural Households in the KassenaNankana Municipality. A Thesis submitted to the School of Graduate Studies, Kwame Nkrumah University of Science and Technology, Kumasi in partial fulfilment of the requirements for the degree of Master of Science in Development Policy and Planning, (2014), Accessed on 12/02/2016 at ir.knust.edu.gh/bitstream/

[12] Webber, P., News from the village: agrarian change in Ghana. Geography Review, 9(3), (1996a.): 25-30.

[13] Blench, R., Working paper: background conditions in Upper East region, Northern Ghana, 2005. LACOSREP II/IFAD,(2006): 1-29.

[14] Kassena-Nankana Municipal Assembly (KNMA)., Municipal Medium-Term Development Plan, 2014-2017, Navrongo- Ghana, (2014).

[15] Creswell, J.W., Research Design: Qualitative, Quantitative and Mixed Method Approaches. SAGE Publications, Inc, (2009).

[16] Israel, G.D., Determining Sample Size. University of Florida. IFAS Extensions, (2013).

[17] Ghana Statistical Service., Ghana Living Standards Survey: Round Six, Main Report. Ghana Statistical Service, (2014).

[18] Ministry of Environment, Science, Technology and Innovation, Republic of Ghana., Ghana Climate Change Policy. MESTI: Accra-Ghana, (2013).

[19] Whitehead, A., and Tsikata, D., Policy discourses on women's land rights in Sub-Saharan Africa: The implications of the re-turn to the Customary. Journal of Agrarian Change, 3(1- 2), (2003): 67-112.

[20] Paavola, J., Livelihoods, vulnerability and adaptation to climate change in Morogoro, Tanzania. Environmental Science \& Policy, 11(7), (2008): 642-654.

[21] Denton, F., Climate change vulnerability, impacts, and adaptation: why does gender matter? Gender \& Development, 10(2), (2002): 10-20. 